\title{
HOW INDUSTRY 4.0 RESHAPES THE WORLD: RECOMMENDATIONS BASED ON COMPLEX GRAPH NETWORK ANALYSIS
}

\author{
Zhou, Rongyan; \\ Stal-Le Cardinal, Julie \\ Université Paris-Saclay, CentraleSupélec
}

\begin{abstract}
Industry 4.0 is a great opportunity and a tremendous challenge for every role of society. Our study combines complex network and qualitative methods to analyze the Industry 4.0 macroeconomic issues and global supply chain, which enriches the qualitative analysis and machine learning in macroscopic and strategic research. Unsupervised complex graph network models are used to explore how industry 4.0 reshapes the world. Based on the in-degree and out-degree of the weighted and unweighted edges of each node, combined with the grouping results based on unsupervised learning, our study shows that the cooperation groups of Industry 4.0 are different from the previous traditional alliances. Macroeconomics issues also are studied. Finally, strong cohesive groups and recommendations for businessmen and policymakers are proposed.
\end{abstract}

Keywords: Industry 4.0, Machine learning, Business models and considerations, Decision making, Big data

Contact:

Zhou, Rongyan

Université Paris-Saclay, CentraleSupélec

Industrial Engineering Research Department(LGI)

France

rongyan.zhou@centralesupelec.fr 


\section{INTRODUCTION}

Industry 4.0 is a great opportunity and a tremendous challenge for every role of society. What impact will Industry 4.0 bring; how to adjust the strategy according to the new situation to deal with the opportunities and challenges brought by Industry 4.0 have been an emerging topic. As a concentration point, Industry 4.0 has been pondered and evaluated by various scholars. (Schneider, 2018) distinguished Industry 4.0 from digitalization and computer-integrated manufacturing to spot managerial challenges of Industry 4.0. (Kamble, Gunasekaran and Gawankar, 2018) learned Industry 4.0 from a sustainable perspective and proffered a sustainable Industry 4.0 framework. (Alcácer and Cruz-Machado, 2019) weighed up new technologies that may come forth in manufacturing systems, and mapped out to manufacturing systems composed by new technologies. (Bodkhe et al., 2020) presented a systematic review of various blockchain-based solutions and their applicability in various Industry 4.0-based applications. (Zhou and Le Cardinal, 2019) concentrated on the impacts of the manufacturing sector and the financial and economic sectors brought by Industry 4.0 technologies.

It is not difficult to see that the trend of intelligence in the industry 4.0 era has made the industry, especially the manufacturing industry, different from before. For instance, (Matsukawa, Minner and Nakashima, 2020) believed abundant economic thought seeks to rewrite economic rules. Also, (Glawe and Wagner, 2020) modified the middle-income trap concept against the background of the Fourth Industrial Revolution and the challenges of automation. As shown above, we can see that the impact of Industry 4.0 is multifaceted, enormous, and far-reaching. Industry 4.0 will affect the production mode, production costs, and labor costs of companies through emerging technologies to change corporate strategies; changes in corporate strategies will promote changes in the global supply chain system and further affect the macroeconomy. This is also as (Matsukawa, Minner and Nakashima, 2020) pointed out that industry has changed significantly in the last two decades; both the macroeconomy, the micro economy, and operation management are facing a big challenge in Industry 4.0. Moreover, (Kovacs, 2018) also called for a broader research canvas for new economic thinking supporting structural change policies.

At present, most of the research on Industry 4.0 strategy focuses on the strategy for specific enterprise types, the implementation of technology, and the supply chains' challenges. For example, (Zhou and Stal-Le Cardinal, 2020) investigated multi-tier supply chains using natural language processing models. (Makarov and Khorosheva, 2019) showed that digitization affects the appearance of new and changes existing business models; owing to the modernization of glass production, the productivity of labor in this industry can be substantially increased on the basis of Industry 4.0 principles by reducing the gap with the industrially developed countries. Also, most of the research on the Industry 4.0 economy focuses on specific aspects of the economic phenomenon brought by Industry 4.0 and Industry 4.0's impacts on a particular region. Such as, (Luthra et al., 2020) investigates the critical drivers of Industry 4.0 to achieve high triple bottom line (ecological-economic-social) gains in SCs by taking an example from India, which helped managers, practitioners, and policymakers interested in Industry 4.0 applications to diffuse sustainability in supply chains. Hence, few studies explore global economic challenges caused by changes in the global clustering perspectives. As (Stentoft and Rajkumar, 2020) mentioned, company location is a new choice facing the background of Industry 4.0. In other words, technological and policy barriers and cost advantages among regions are undergoing new changes. Therefore, the considerations and priorities for industrial Investment are also changing under Industry 4.0.

In the circumstances, the degree of regional inter-dependence would affect the investment efficiency and investment risk of enterprises either in the financial sector or industry. Such as geological disasters, outbreaks of epidemic diseases, political conflicts, or other emergencies would have a profound impact on the local, closely connected regions and companies that invest in appropriate locations. Therefore, under the background of Industry 4.0, which regional clusters are more closely connected, and how should enterprises consider the problem of transnational location selection, which are challenges and confusions for practitioners and scholars. Since industrial Investment often needs a long payback period, it is more urgent to solve the above problems for industrial Investment. These issues are also crucial for practitioners in the financial industry who are concerned about industry. Therefore, our study focuses on the problems mentioned above to be solved.

In this paper, we first clean the Industry 4.0 data in the Trendeo database. Then unsupervised learning that could be used for community detection is analyzed and screened. Next, we apply the selected 
unsupervised algorithm to process the clustering for 141 countries and regions worldwide based on the cleaned data. Finally, the analysis of the global clustering from a global perspective is propounded. Our study shows an innovative methodology and valuable analysis for AI and the DataDriven Economy in Industry 4.0.

\section{METHODOLOGY}

The primary purpose of this paper is to present a reasonable clustering based on different criteria and make suggestions and analysis of the global supply chain for enterprises and organizations. Furthermore, in passing, taking a glance at the macroeconomy through our analysis system.

\subsection{Methodology}

As mentioned above, few studies explored how industry 4.0 reshapes country/regional clusters from a global perspective. The data involved in our study can be regarded as graph data; that is, the country is regarded as the nodes, and the relationship between regions is regarded as the edges, so the algorithms for handling graph data are very suitable to achieve our research objectives. Restricted by technology, past macro studies mostly used econometric methods or qualitative analysis methods. Such as (Jung and Lim, 2020) constructed a simultaneous equation model setting the adoption of industrial robots, employment growth, and labor costs as endogenous variables using the panel data constructed from 42 countries for the years 2001-2017. Nevertheless, this kind of method is quite challenging in processing graph data. With the development of machine learning, machine learning for fitting and prediction in economic management has also been deployed, and most of the machine learning methods for graph data are used in image recognition. As an illustration (Wu et al., 2019) proposed an unsupervised graph association (UGA) approach to address the unsupervised person re-identification problem. Some studies have used community detection algorithms to analyze social networks with graph data. To illustrate, (Kanavos et al., 2018) proposed a method based on the emotional content of each post for identifying influential communities in social networks with the use of users' emotional behavior and users' influence in a specific timeframe. However, few scholars have applied machine learning based on community detection to macroeconomic graph data analysis. Our study applies the modularity-based unsupervised model to analyze the graph data of industry 4.0 to overcome the defects of traditional econometrics methods and give play to the advantages of machine learning in graphs.

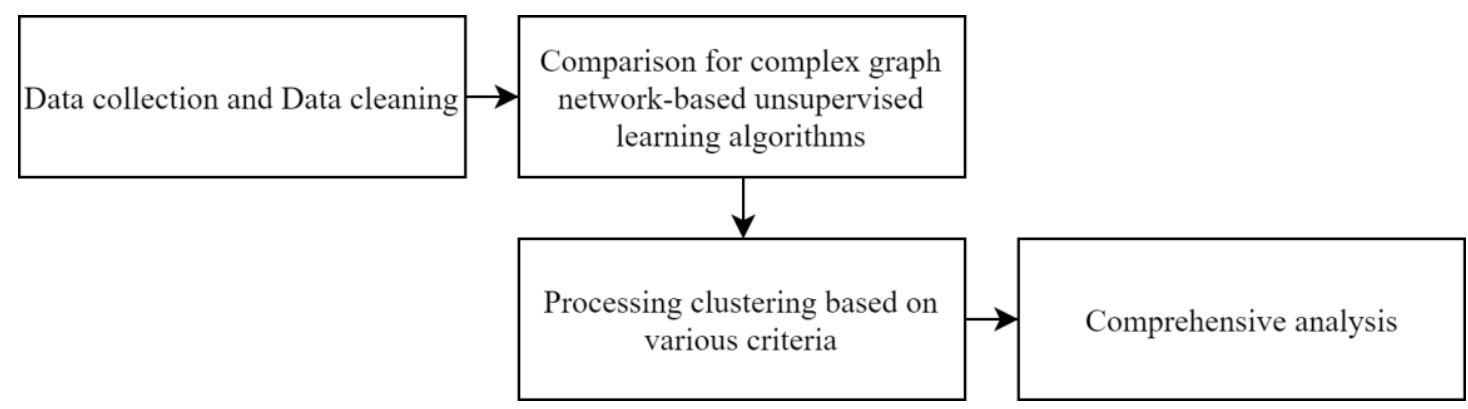

Figure 1. Process to analyze graph data of industry 4.0

\subsection{Data process}

Industry 4.0 investment and employment data come from the Trendeo database. David Cousquer, the CEO of Trendeo, define Trendeo I\&S as a database that tracks industrial Investment worldwide, by the number of projects, by amount invested, and along with Industry 4.0 criteria. The Trendeo database we use has only started to collect data in 2015. The deployment and development of Industry 4.0 in some countries have only been launched in recent years. The data in many countries are still very scarce. We set data from 2016 to 2019 as our input data. Here we add up the investment amount and the number of new jobs between each of the two countries or regions in the past four years into one item as the graph network's edge. Use each country or region as a node. Also, to select each region's features more comprehensively and objectively to perfect our analysis, the World Bank-World Development Indicators (WDI) is used to screen regional features. The countries/regions recorded in both Trendeo and WDI were selected as targets. Since some countries and regions are within the 
World Bank's statistical scope, but there are almost no data, we choose GDP, a relatively comprehensive indicator of the current World Bank statistics, as the frame of reference. If a country or region has no statistical data in the GDP statistics in the recent ten years, the region will be deleted. Finally, 141 countries/regions were set as the research objectives and the node of the graph. Besides, to measure each country/region's technological development level, we use data from the World Intellectual Property Organization (WIPO) to assist our analysis.

\section{UNSUPERVISED LEARNING}

As stated by many researchers, if the technologically inferior country's labor cost advantage is replaced by new technology, countries with the technological advantage will no longer have to invest and build factories in regions with low labor costs. There will be fewer transactions between countries with technological advantages and technological disadvantages. They are more inclined to seek complementary cooperation within their groups, which is more likely to lead to a more significant gap. At this point, exploring the clustering situation among countries and regions through interactive data is an intuitive way to verify the above problems.

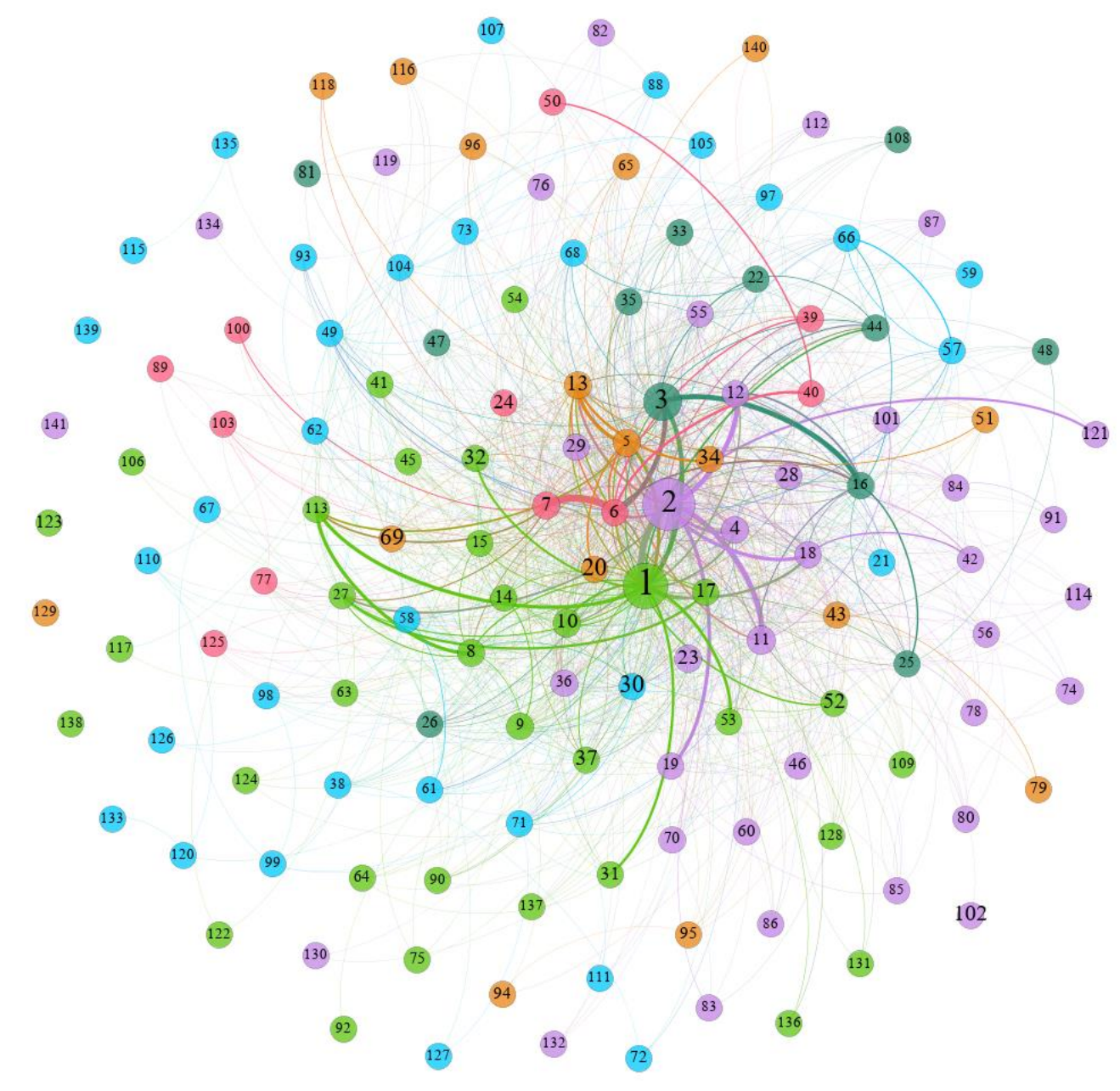

Figure 2. Clustering based on Industry 4.0 investment amount (For example, node 6 (the United Kingdom) ranks 6 in GDP in 2019 and ranks 15 in total patent grants in 2018. The link line of node 7 (France) is thicker than that of node 40 (Egypt), which means the investment amount between node 6 and node 7 is larger than node 6 and node 40.)

As (Fortunato, 2010) pointed out that community detection is very applicable and essential to systems represented as graphs. Moreover, (Fortunato and Hric, 2016) said that communities are usually groups of vertices having a higher probability of being connected than other groups' members, though other patterns are possible. Among the unsupervised community detection models, spectral clustering (von 
Luxburg, 2007), the Louvain model (Blondel et al., 2008), Info map model (Rosvall, Axelsson and Bergstrom, 2009), and so on are all models that have proven worth considering. Graph is a vital data representation that appears in a wide diversity of real-world scenarios and our study. Effective graph analytics provides a deeper understanding of what is behind the data. (Cai, Zheng and Chang, 2018) As said by (Jebabli et al., 2018), although many community detection algorithms have been proposed, there is no unified conclusion on various algorithms' performance.

Still, spectral clustering needs to specify the number of categories artificially, and the classification is unstable, so it is abandoned. The Modularity based Infomap and Louvain algorithms are currently unsupervised community classification algorithms that do not need to specify the number of categories in advance. In addition, since the current complex graph network can only be applied to heterogeneous graphs, we construct two graphs here, namely, $G_{\text {invest }}=\left(V_{\text {invest }}, E_{\text {invest }}\right)$ and $G_{j o b}=\left(V_{j o b}, E_{j o b}\right)$. Graph $G_{\text {invest }}$ is composed of $V_{\text {invest }}$ (141 countries/regions as nodes) and $E_{\text {invest }}$ (Investment as the edges and investment amount as the weight); Graph $G_{j o b}$ is composed of $V_{j o b}$ (141 countries/regions as nodes) and $E_{j o b}$ (new jobs as the edges and new jobs number as the weight). That is, we take the investment amount and the number of new jobs of the two regions as weights of edges respectively, and each country/region as the node of the graph. Since we are committed to exploring the relationship between nodes, neither graph contains self-loops. We experimented with both algorithms.

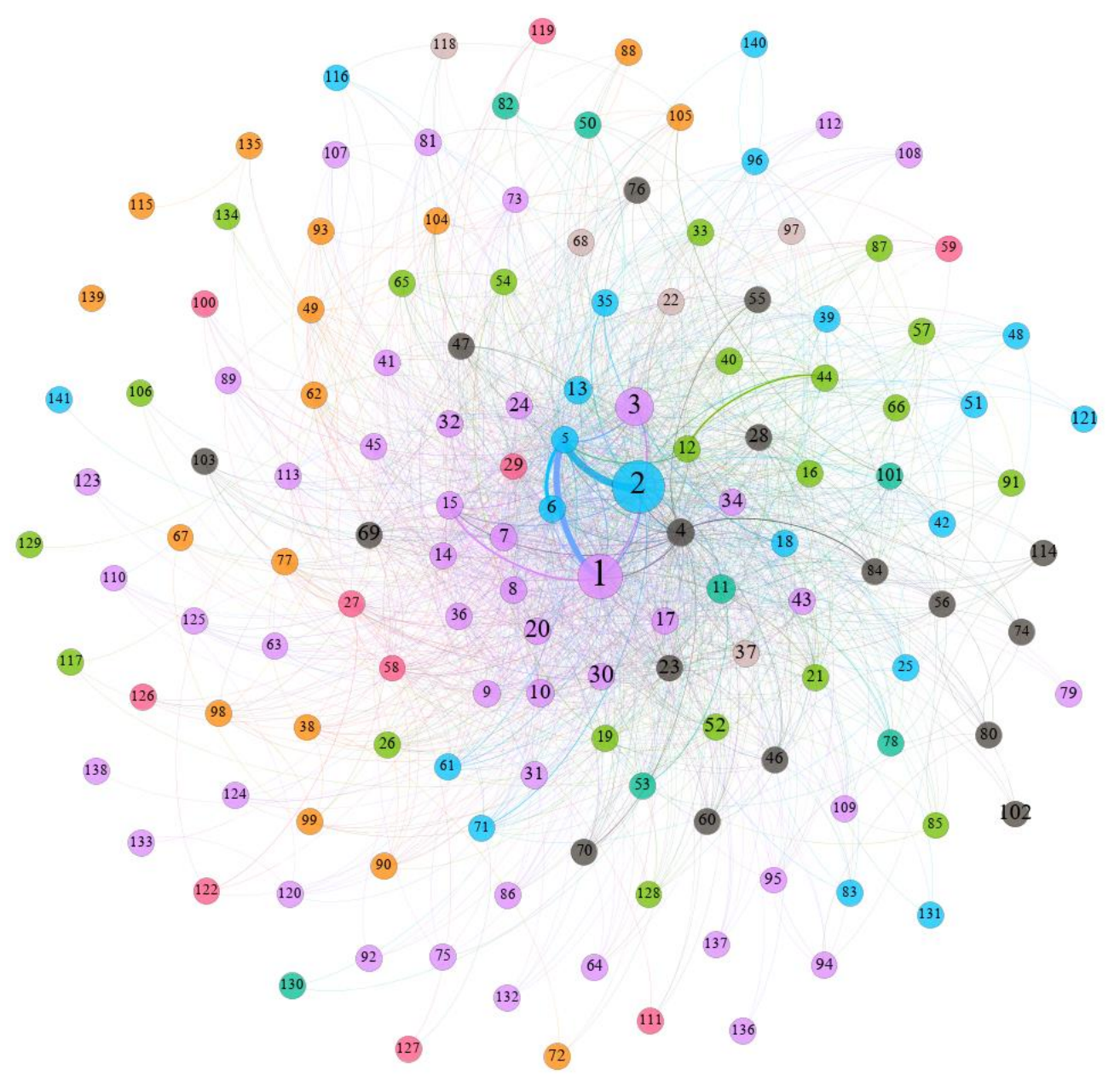

Figure 3 Clustering based on new jobs brought by Industry 4.0 invest (For example, node 5 (India) ranks 5 in GDP in 2019 and ranks 8 in total patent grants in 2018. The link line of node 6 (the United Kingdom) is thicker than that of node 3 (Japan), which means the new jobs created between node 5 and node 8 are larger than node 5 and node 3.)

In the experiment, we can only take Investment and employment as a single indicator of the input edge for heterogeneous graphs, but our research is committed to exploring the global cluster effect of industry 4.0 through at least the dual indicators. So, we temporarily regard the intersection of 
investment edge results and employment edge results as the clustering result. That is, the cluster countries are close partners in both Investment and job creation. It is worth noting that undirected edges are required in Louvain models (Blondel et al., 2008), whereas directed edges can be entered in the Infomap model (Rosvall and Bergstrom, 2008). Therefore, in the Louvain model, we use the sum of Investment and new jobs between the two regions as the edge, while the edge in Infomap followed the ground truth. It also implies the limitation of the Louvain model in the application. Also, the study of (Alzahrani and Horadam, 2016) showed that the clusters found by Infomap are meaningful and better represent ground truth in the bipartite network than those found by Louvain. Therefore, we used the Louvain model when using the undirected graph as input, the Infomap model used the directed graph as input, and finally integrated the two models' results to make the comprehensive analysis. The clustering results are shown in Figure 2 and Figure 3, respectively.

In figure 2 and figure 3, the node's number is the ranking of GDP in 2019 and the label of each country/region in this paper (See appendix A for details of node labels of countries/regions); the line thickness represents the Industry 4.0 investment amount in figure 2 and new jobs brought by Industry 4.0 investment in figure 3, the thicker the line, the larger weights for the line; the line's color is the aggregate color of the node colors at both ends. The color represents the groups, and the nodes of the same color are a group. It is worth noting that the blue nodes in Figure 2 and the khaki nodes in Figure 3 are nodes that are not in the intersection of clustering of Louvain and Infomap methods, which means that these countries/regions do not form a strong alliance with other countries/regions. The nodes' size represented the total patent grants in 2018; the larger the nodes, the larger the total patent grants. It can be intuitively seen from figure 2 and figure 3 that the nodes' numbers with dense edges in the center of figure 2 and figure 3 are relatively small. Nodes' sizes are relatively large in this area, which means that they are mostly countries with high GDP and high patent grants. However, we can approximately treat the nodes in the graph as uniformly distributed in a circular disc. Hence, the central region covers far fewer nodes than the nodes in the graph's non-central region. To some extent, this also indicates that only a few countries have played an important role in Industry 4.0, while many countries have not benefited from industry 4.0, especially the points with few edges in the figure, which tend to belong to countries with low GDP and fewer patents granted. Whether this will lead to further widening of the gap between rich and poor among countries/regions in the future is also a question worth thinking about.

\section{OUTPUT AND DISCUSSION}

In order to better explore the details of the nodes in the graph, we have made statistics on the degree of each node. We denote the out-degree of the node with weighted edges in Figure 2 as Investment abroad; the in-degree of the node with weighted edges as Investment received; the out-degree of the nodes without weighted edges as Countries numbers of Investment abroad; and the in-degree of the node without weights as Countries numbers of Investment received. In Figure 3, similarly, the outdegree of the node's weighted edge is denoted as Jobs created abroad; the in-degree of the node's weighted edge is denoted as Foreign Investment creates jobs at home; the out-degree of node's unweighted edge is denoted as Countries creating jobs abroad; the in-degree of the node's unweighted edge is denoted as Countries accepting foreign job creation. As shown in Table 1, both the amount of foreign Investment and the number of foreign investment countries traditional developed countries occupy the list. Also, as an emerging economy, China occupies an important position in Industry 4.0. Australia, Russia, Mexico, India, Indonesia, and Vietnam listed in the top 5 ranks for the amount of received foreign Investment. This includes both developing countries and developed countries, and Trendeo investment and employment data show signed contract data, that is to say, many of which Investment and employment will truly implement in the next few years, so, from that perspective, in recent years, Industry 4.0 will not deprive the labor cost advantage. Hence, countries with a labor cost advantage still have a particular advantage in attracting Investment and employment. In addition, emerging economies such as China and India are eye-catching in Industry 4.0, but Industry 4.0 is reshaping the world. This is different from our traditional cognition of alliances. For example, node 4 (Germany) and Node 8 (Italy) are both EU countries, but they do not belong to the same group in Figure 2 and Figure 3. Therefore, we can see the differences between the cooperative groups in Industry 4.0 and the previous division. Of course, this paper only covers the cooperation in industry 4.0 , which does not mean that the original economic or political union has broken down. 
Table 1. Rank of degree statistics

\begin{tabular}{|c|c|c|c|c|c|c|c|}
\hline $\begin{array}{c}\text { Investment } \\
\text { abroad } \\
\text { top } 5\end{array}$ & $\begin{array}{l}\text { Investmen } \\
\text { t received } \\
\text { top } 5\end{array}$ & $\begin{array}{c}\text { Countries } \\
\text { numbers of } \\
\text { Investment } \\
\text { abroad top } 5\end{array}$ & $\begin{array}{l}\text { Countries } \\
\text { numbers of } \\
\text { Investment } \\
\text { received } \\
\text { top } 5\end{array}$ & $\begin{array}{c}\text { Jobs } \\
\text { created } \\
\text { abroad } \\
\text { top 5 }\end{array}$ & $\begin{array}{l}\text { Foreign } \\
\text { Investment } \\
\text { creates jobs } \\
\text { at home } \\
\text { top } 5\end{array}$ & $\begin{array}{c}\text { Countries } \\
\text { creating } \\
\text { jobs } \\
\text { abroad } \\
\text { Top } 5\end{array}$ & $\begin{array}{c}\text { Countries } \\
\text { accepting } \\
\text { foreign } \\
\text { job } \\
\text { creation } \\
\text { Top 5 }\end{array}$ \\
\hline China & $\begin{array}{l}\text { United } \\
\text { States }\end{array}$ & United States & India & China & India & $\begin{array}{l}\text { United } \\
\text { States }\end{array}$ & $\begin{array}{l}\text { United } \\
\text { States }\end{array}$ \\
\hline $\begin{array}{l}\text { United } \\
\text { States }\end{array}$ & China & China & $\begin{array}{l}\text { United } \\
\text { States }\end{array}$ & $\begin{array}{l}\text { United } \\
\text { States }\end{array}$ & $\begin{array}{l}\text { United } \\
\text { States }\end{array}$ & China & India \\
\hline Japan & $\begin{array}{l}\text { United } \\
\text { Kingdom }\end{array}$ & France & $\begin{array}{l}\text { United } \\
\text { Kingdom }\end{array}$ & Germany & Mexico & Japan & $\begin{array}{l}\text { United } \\
\text { Kingdom }\end{array}$ \\
\hline France & Australia & $\begin{array}{l}\text { United } \\
\text { Kingdom }\end{array}$ & Russia & Japan & Vietnam & Germany & Germany \\
\hline $\begin{array}{l}\text { United } \\
\text { Kingdom }\end{array}$ & Indonesia & Germany & Mexico & $\begin{array}{l}\text { United } \\
\text { Kingdom }\end{array}$ & $\begin{array}{l}\text { United } \\
\text { Kingdom }\end{array}$ & France & Canada \\
\hline
\end{tabular}

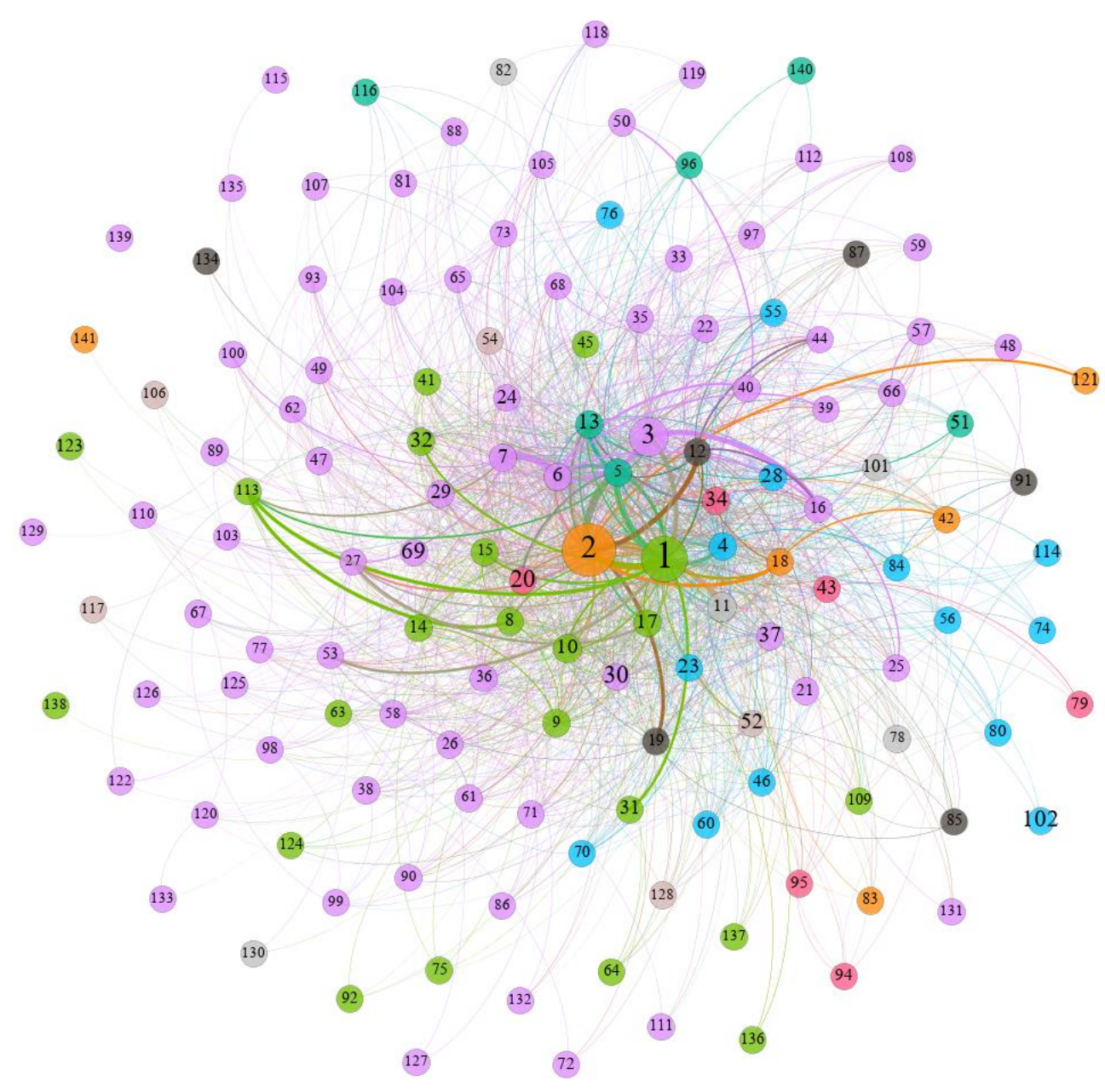

Figure 4 Intersections of industry 4.0 investment and new jobs

For multinational companies, the closer the relationship between the two countries, the lower the probability of conflict between them. Therefore, setting up the supply chain in a group with a closer cooperative relationship will be more conducive to improving its supply chain's stability. The grouping is derived from objective data and proven algorithms, and most of the Industry 4.0 data involves the 
manufacturing industry and other industrial sectors with long payback periods. This means that these groups are difficult to change in the short term. There are essential references for companies to choose suppliers and select locations to build factories. In order to make up for the shortcomings of only using a single index to divide the groups in Figures 2 and 3, Figure 4 shows the intersection of the groups in Figures 2 and 3. We call these intersections strong cohesive groups. That is, in a more conservative sense, the probability of conflicts within the strong cohesion group is lower, which also provides a reference for corporate decision-making. The meanings of numbers and nodes are the same as those in Figures 2 and 3. The purple nodes in Figure 4 are ungrouped and show all connections of normalized investment amount and new jobs number. Readers can also combine the weights of connected edges and the three grouping situations shown in Figures 2, 3, and 4 to make decisions fitting for themselves.

\section{CONCLUSION}

First of all, this paper makes a macro summary and analysis of the research on industry 4.0 strategy. Subsequently, the unsupervised complex graph network models, modularity-based Louvain and Infomap models are applied to how industry 4.0 reshape the world. Then, based on the in-degree and out-degree of the weighted and unweighted edges of each node, combined with the grouping results based on unsupervised learning, this paper believes that the cooperation group of Industry 4.0 is different from the previous traditional alliances. A new group with 4.0 as the standard is emerging, and the new group does not separate traditional developed countries from developing countries. Industry 4.0 technology cannot be the disappearance of labor cost advantages. Countries with labor cost advantages in recent years still have their advantages. Finally, strong cohesive groups and recommendations for businesses and policymakers are proposed.

This study combined complex network and qualitative methods to analyze the Industry 4.0 macroeconomic problems, which enriches the qualitative analysis and machine learning in macroscopic research and strategy research. The application of multiple and the advanced model significantly improves repeatability and objectivity. The analysis of this paper has excellent reference significance for policymakers, researchers, and enterprises such as by laying out the industrial chain or supply chain in the same strong cohesive group or placing backup suppliers in countries/regions that are not in the three intersections to enhance the industrial chain or supply chain's stability.

\section{LIMITATION AND OUTLOOK}

Since the current graph network algorithms only support heterogeneous graphs, the intersection cannot cover all nodes when the strengths of the two models are taken, so in the future, using supervised learning as a supplement to this research will be considered. In addition, in the case that the algorithm only supports heterogeneous graphs, taking intersection just identified the limited grouping of nodes given by strong cohesive groups. Therefore, how to aggregate the information of two kinds of edges to fit for heterogeneous graph analysis is also the focus of future research. What is more, since Industry 4.0 is still in its infancy and data is limited, this study can only process static analysis. With the increase of data, time series analysis based on machine learning will also be the next research direction.

\section{ACKNOWLEDGMENTS}

Thanks to manpower, material, and funding support provided by the Industrial Engineering Laboratory (LGI) of CentraleSupelec, University of Paris Saclay. And we would like to extend my sincere gratitude to the Industry 4.0 data provided by the Trendeo I\&S to support our research.

\section{APPENDIX A. COUNTRY/REGION LABELS}

\begin{tabular}{|c|c|c|c|c|c|}
\hline Country/region & Node label & Country/region & Node label & Country/region & Node label \\
\hline United States & 1 & Iraq & 48 & Estonia & 95 \\
\hline China & 2 & Peru & 49 & Nepal & 96 \\
\hline Japan & 3 & Greece & 50 & Cambodia & 97 \\
\hline Germany & 4 & New Zealand & 51 & El Salvador & 98 \\
\hline India & 5 & Qatar & 52 & Honduras & 99 \\
\hline
\end{tabular}




\begin{tabular}{|c|c|c|c|c|c|}
\hline United Kingdom & 6 & Kazakhstan & 53 & $\begin{array}{c}\text { Papua New } \\
\text { Guinea }\end{array}$ & 100 \\
\hline France & 7 & Algeria & 54 & Cyprus & 101 \\
\hline Italy & 8 & Hungary & 55 & Iceland & 102 \\
\hline Brazil & 9 & Ukraine & 56 & Senegal & 103 \\
\hline Canada & 10 & Kuwait & 57 & Zambia & 104 \\
\hline Russia & 11 & Morocco & 58 & Zimbabwe & 105 \\
\hline South Korea & 12 & Ecuador & 59 & Afghanistan & 106 \\
\hline Australia & 13 & Slovakia & 60 & Botswana & 107 \\
\hline Spain & 14 & Ethiopia & 61 & Laos & 108 \\
\hline Mexico & 15 & Kenya & 62 & Georgia & 109 \\
\hline Indonesia & 16 & Angola & 63 & Mali & 110 \\
\hline Netherlands & 17 & $\begin{array}{l}\text { Dominican } \\
\text { Republic }\end{array}$ & 64 & Gabon & 111 \\
\hline Saudi Arabia & 18 & Sri Lanka & 65 & Jamaica & 112 \\
\hline Turkey & 19 & Oman & 66 & Mozambique & 113 \\
\hline Switzerland & 20 & Guatemala & 67 & Malta & 114 \\
\hline Poland & 21 & Myanmar & 68 & Benin & 115 \\
\hline Thailand & 22 & Luxembourg & 69 & Mauritius & 116 \\
\hline Sweden & 23 & Bulgaria & 70 & Madagascar & 117 \\
\hline Belgium & 24 & Ghana & 71 & Mongolia & 118 \\
\hline Iran & 25 & Panama & 72 & Armenia & 119 \\
\hline Argentina & 26 & Tanzania & 73 & Guinea & 120 \\
\hline Nigeria & 27 & Belarus & 74 & Brunei & 121 \\
\hline Austria & 28 & Costa Rica & 75 & Niger & 122 \\
\hline $\begin{array}{l}\text { United Arab } \\
\text { Emirates }\end{array}$ & 29 & Croatia & 76 & Bahamas & 123 \\
\hline Norway & 30 & Ivory Coast & 77 & Macedonia & 124 \\
\hline Israel & 31 & Uzbekistan & 78 & Namibia & 125 \\
\hline Ireland & 32 & Uruguay & 79 & Chad & 126 \\
\hline Philippines & 33 & Lithuania & 80 & $\begin{array}{l}\text { Republic of } \\
\text { the Congo }\end{array}$ & 127 \\
\hline Singapore & 34 & Slovenia & 81 & Rwanda & 128 \\
\hline Malaysia & 35 & Lebanon & 82 & Haiti & 129 \\
\hline South Africa & 36 & Libya & 83 & Kyrgyzstan & 130 \\
\hline Denmark & 37 & Serbia & 84 & Tajikistan & 131 \\
\hline Colombia & 38 & Azerbaijan & 85 & Malawi & 132 \\
\hline Bangladesh & 39 & $\begin{array}{c}\text { Democratic } \\
\text { Republic of the } \\
\text { Congo }\end{array}$ & 86 & Mauritania & 133 \\
\hline Egypt & 40 & Jordan & 87 & Fiji & 134 \\
\hline Chile & 41 & Bolivia & 88 & Togo & 135 \\
\hline Pakistan & 42 & Tunisia & 89 & Guyana & 136 \\
\hline Finland & 43 & Cameroon & 90 & Sierra Leone & 137 \\
\hline Vietnam & 44 & Bahrain & 91 & Liberia & 138 \\
\hline Romania & 45 & Paraguay & 92 & Burundi & 139 \\
\hline Czechia & 46 & Uganda & 93 & Bhutan & 140 \\
\hline Portugal & 47 & Latvia & 94 & Vanuatu & 141 \\
\hline
\end{tabular}




\section{REFERENCES}

Alcácer, V. and Cruz-Machado, V. (2019) 'Scanning the industry 4.0: A literature review on technologies for manufacturing systems', Engineering Science and Technology, an International Journal. Elsevier, 22(3), pp. 899-919.

Alzahrani, T. and Horadam, K. J. (2016) 'Community Detection in Bipartite Networks: Algorithms and Case studies BT - Complex Systems and Networks: Dynamics, Controls and Applications', in Lü, J. et al. (eds). Berlin, Heidelberg: Springer Berlin Heidelberg, pp. 25-50. https://dx.doi.org/10.1007/978-3-662-47824-0_2.

Blondel, V. D. et al. (2008) 'Fast unfolding of communities in large networks', Journal of Statistical Mechanics: Theory and Experiment. IOP Publishing, 2008(10), p. P10008. https://dx.doi.org/10.1088/1742$5468 / 2008 / 10 / \mathrm{p} 10008$.

Bodkhe, U. et al. (2020) 'Blockchain for Industry 4.0: A Comprehensive Review', IEEE Access, 8, pp. 7976479800. https://dx.doi.org/10.1109/ACCESS.2020.2988579.

Cai, H., Zheng, V. W. and Chang, K. C. (2018) 'A Comprehensive Survey of Graph Embedding: Problems, Techniques, and Applications', IEEE Transactions on Knowledge and Data Engineering, 30(9), pp. 16161637. https://dx.doi.org/10.1109/TKDE.2018.2807452.

Fortunato, S. (2010) 'Community detection in graphs', Physics Reports, 486(3), pp. 75-174. doi: https://doi.org/10.1016/j.physrep.2009.11.002.

Fortunato, S. and Hric, D. (2016) 'Community detection in networks: A user guide', Physics Reports, 659, pp. 1-44. doi: https://doi.org/10.1016/j.physrep.2016.09.002.

Glawe, L. and Wagner, H. (2020) 'The Middle-Income Trap 2.0: The Increasing Role of Human Capital in the Age of Automation and Implications for Developing Asia', Asian Economic Papers. MIT Press, 19(3), pp. 40-58. https://dx.doi.org/10.1162/asep_a_00783.

Jebabli, M. et al. (2018) 'Community detection algorithm evaluation with ground-truth data', Physica A: Statistical Mechanics and its Applications, 492, pp. 651-706. doi: https://doi.org/10.1016/j.physa.2017.10.018.

Jung, J. H. and Lim, D.-G. (2020) 'Industrial robots, employment growth, and labor cost: A simultaneous equation analysis', Technological Forecasting and Social Change, 159, p. 120202. doi: https://doi.org/10.1016/j.techfore.2020.120202.

Kamble, S. S., Gunasekaran, A. and Gawankar, S. A. (2018) 'Sustainable Industry 4.0 framework: A systematic literature review identifying the current trends and future perspectives', Process Safety and Environmental Protection. Elsevier, 117, pp. 408-425.

Kanavos, A. et al. (2018) 'Emotional community detection in social networks', Computers \& Electrical Engineering, 65, pp. 449-460. doi: https://doi.org/10.1016/j.compeleceng.2017.09.011.

Kovacs, O. (2018) 'The dark corners of industry 4.0 - Grounding economic governance 2.0', Technology in Society, 55, pp. 140-145. doi: https://doi.org/10.1016/j.techsoc.2018.07.009.

Luthra, S. et al. (2020) 'Industry 4.0 as an enabler of sustainability diffusion in supply chain: an analysis of influential strength of drivers in an emerging economy', International Journal of Production Research. Taylor \& Francis, 58(5), pp. 1505-1521. https://dx.doi.org/10.1080/00207543.2019.1660828.

von Luxburg, U. (2007) 'A tutorial on spectral clustering', Statistics and Computing, 17(4), pp. 395-416. https://dx.doi.org/10.1007/s11222-007-9033-z.

Makarov, R. I. and Khorosheva, E. R. (2019) 'Salient Aspects of the Implementation of Digital Economics in Glass Plants in Russia', Glass and Ceramics, 75(11), pp. 438-440. https://dx.doi.org/10.1007/s10717-019-00107-4.

Matsukawa, H., Minner, S. and Nakashima, K. (2020) 'Editorial: Industry 4.0 and Production Economics', International Journal of Production Economics, 226, p. 107666. doi: https://doi.org/10.1016/j.ijpe.2020.107666.

Rosvall, M., Axelsson, D. and Bergstrom, C. T. (2009) 'The map equation', The European Physical Journal Special Topics, 178(1), pp. 13-23. https://dx.doi.org/10.1140/epjst/e2010-01179-1.

Rosvall, M. and Bergstrom, C. T. (2008) 'Maps of random walks on complex networks reveal community structure', Proceedings of the National Academy of Sciences, 105(4), pp. 1118 LP - 1123. https://dx.doi.org/10.1073/pnas.0706851105.

Schneider, P. (2018) 'Managerial challenges of Industry 4.0: an empirically backed research agenda for a nascent field', Review of Managerial Science, 12(3), pp. 803-848. https://dx.doi.org/10.1007/s11846-018-0283-2.

Stentoft, J. and Rajkumar, C. (2020) 'The relevance of Industry 4.0 and its relationship with moving manufacturing out, back and staying at home', International Journal of Production Research. Taylor \& Francis, 58(10), pp. 2953-2973. https://dx.doi.org/10.1080/00207543.2019.1660823.

$\mathrm{Wu}$, J. et al. (2019) 'Unsupervised graph association for person re-identification', in Proceedings of the IEEE International Conference on Computer Vision, pp. 8321-8330.

Zhou, R. and Le Cardinal, J. (2019) 'Exploring the Impacts of Industry 4.0 from a Macroscopic Perspective', in Proceedings of the Design Society: International Conference on Engineering Design. Cambridge University Press, pp. 2111-2120.

Zhou, R. and Stal-Le Cardinal, J. (2020) 'The main trends for multi-tier supply chain in Industry 4.0 based on Natural Language Processing', Computers in Industry. 